\title{
Internal solitary waves in Upper Lake Constance
}

\author{
M. Preusse $\cdot$ F. Peeters
}

\begin{abstract}
The conceptual hypothesis that internal solitary waves (ISWs) in lakes are generated at fronts of basin-scale internal waves, propagate until they break at the terminal boundary and extend over the lake width in cross-propagation direction is tested using temperature and current profiles measured in Upper Lake Constance. Trains of ISWs of depression propagate in close association with the front of a Kelvin wave at almost constant phase speed from the main basin of Upper Lake Constance to the western shore of a sub-basin, Lake Überlingen. The trough of the ISWs extends over the entire basin width in narrow Lake Überlingen but not in the wider main basin. A substantial part of the ISWs propagating towards the western terminal boundary did not return, suggesting wave-energy loss due to wave breaking. Close to the shorelines parallel to their propagation direction the amplitudes of the ISWs are diminished. Temperature inversions suggest that wave breaking is occurring at these boundaries, but also in the open water where breaking events extend along the width of the ISW front. The heterogeneity of ISW breaking
\end{abstract}

Guest editors: D. Straile, D. Gerdeaux, D. M. Livingstone, P. Noges, F. Peeters \& K. O. Rothhaupt / European Large Lakes III. Large lakes under changing environmental conditions

M. Preusse $\cdot$ F. Peeters $(\square)$

Environmental Physics, Limnological Institute, University of Konstanz, Mainaustr. 252, 78464 Constance, Germany e mail: Frank.Peeters@uni konstanz.de suggests that the associated mixing and vertical fluxes of plankton and nutrients across the thermocline are highly variable in space and time.

Keywords Internal waves - Solitary waves · Wave breaking $\cdot$ Mixing

\section{Introduction}

Internal solitary waves (ISWs), indicated by a propagating localized coherent vertical displacement of isotherms and a characteristic velocity field, are a frequent phenomenon in lakes (Horn et al., 2001; Hutter, 2012) and in the ocean (e.g. Helfrich \& Melville, 2006). These waves are considered to be the major source of turbulent kinetic energy in the boundary layer of lakes, and thus contribute to resuspension, bio-geochemical fluxes and overall vertical mixing (Ostrovsky et al., 1996; Macintyre et al., 1999; Michallet \& Ivey, 1999; Boegman \& Ivey, 2009). The impact of ISWs, however, depends on the location and timing of the occurrence of the ISWs and hence on their overall propagation pattern.

In many lakes, ISWs are connected to the phase of a basin-scale internal seiche (Thorpe et al., 1972, 1996; Lorke et al., 2006). The interaction of basin-scale waves with topography can generate ISWs and thus cause such a temporal connection (Thorpe et al., 1996). Since sills are known to support the generation of ISWs, the Sill of Mainau (Fig. 1a) may be the location 
of ISW generation in Upper Lake Constance (De La Fuente et al., 2010), but also a location of breaking and transformation of ISWs (Vlasenko \& Hutter, 2002b). In long, narrow lakes, trains of ISWs typically occur in connection with a progressive non-linear internal surge that develops from the steepening of a low-frequency basin-scale internal wave (e.g. Horn et al., 2001; Hutter, 2012 and references therein). The non-linear steepening of basin-scale waves and the generation of ISWs at the steepened front of the resulting progressive surge is often described based on weakly non-linear theory using the Korteweg de Vries (KdV) equation (Hammack \& Segur, 1974). Such an evolution of ISWs from a degenerating long, internal wave has been confirmed in several laboratory experiments (e.g. Ostrovsky \& Stepanyants, 2005). ISWs can also evolve from hydraulic jumps that develop if the flow associated with the basin-scale wave becomes supercritical (Horn et al., 2001). In Cayuga Lake, ISWs were more often associated with hydraulic jumps than with steepened internal surges (Dorostkar \& Boegman, 2013).

ISWs typically propagate through lakes and oceans until they shoal upon sloping topography (e.g. Boegman et al., 2005; Bourgault et al., 2007). Laboratory experiments, numerical experiments and field observations have indicated that these waves can dissipate a large part of their energy during the shoaling process (e.g. Michallet \& Ivey, 1999; Vlasenko \& Hutter, 2002a; Moum et al., 2007). However, based on observations of ISW reflection in a fjord-like system, Bourgault et al. (2011) have suggested that the energy loss of ISWs reflected from steep slopes may be smaller than previously thought.

Field observations of the evolution of ISWs in lakes are comparatively scarce, often limited in spatial extent, and typically focus on measurements along the thalweg. An overview of field experiments addressing solitary waves in lakes is given in Filatov et al. (2012). Studies that have investigated ISW-induced processes in lakes have typically concentrated on observations from very restricted locations. For example, Boegman et al. (2003) employed data from three stations located within $\approx 200 \mathrm{~m}$ of each other to identify the phase velocity of ISWs. In Upper Lake Constance, observations from three near-shore stations located within $\approx 20 \mathrm{~m}$ of each other were the basis for a study on the breaking of ISW's in the thermocline (Preusse et al., 2010). Measurements collected at a single station were used to determine turbulence and mixing due to breaking high-frequency waves in the boundary layer (Lorke, 2007) and to obtain long-term statistics on the occurrence and the amplitudes of ISWs in the open water (Preusse et al., 2012a).

The aim of this study is to provide a basis for the generalization to the basin scale of the information on solitary waves and associated processes available from restricted measuring locations. Utilizing observations from 12 measurement stations, we investigate the horizontal variation in the properties of ISWs and their propagation pattern at the basin scale in Upper Lake Constance. The spatial variation of the properties of the ISWs is studied not only in the direction of propagation, but also orthogonally to the direction of propagation. These measurements thus provide field evidence for the generation, propagation and shape of the ISWs at the basin scale.

\section{Methods}

Site description and data analysis

Field data were collected in Upper Lake Constance (Fig. 1a). The main basin of Upper Lake Constance has a length of $45 \mathrm{~km}$, a maximum width of $14 \mathrm{~km}$, a mean width of $9.3 \mathrm{~km}$, a maximum depth of $250 \mathrm{~m}$ and a mean depth of $100 \mathrm{~m}$ (Bäuerle et al., 1998). A sub-basin, Lake Überlingen, is connected to the main basin at the Sill of Mainau, where the depth of the lake at the thalweg is reduced to $80 \mathrm{~m}$. Lake Überlingen has a length of $20 \mathrm{~km}$, a mean width of $2.3 \mathrm{~km}$ and a maximum depth of $145 \mathrm{~m}$ (Bäuerle et al., 1998).

The spatial dimension of the main basin of Upper Lake Constance is sufficiently large that the Earth's rotation affects the shape of basin-scale internal waves. Kelvin waves with a period of about 4 days, travelling anti-clockwise around the main basin, are a common feature of the wave field in Upper Lake Constance; these Kelvin waves tilt the thermocline upwards towards the shore on the right-hand side (Bäuerle et al., 1998, Appt et al., 2004). In the narrow sub-basin Lake Überlingen, the influence of the Earth's rotation is less visible than in the main basin.

The Earth's rotation is expected to have a significant effect on the structure of the wave motion only at length scales exceeding the internal Rossby radius (e.g. Mortimer, 1974; Hutter et al., 1991). The internal Rossby radius $r$ is 

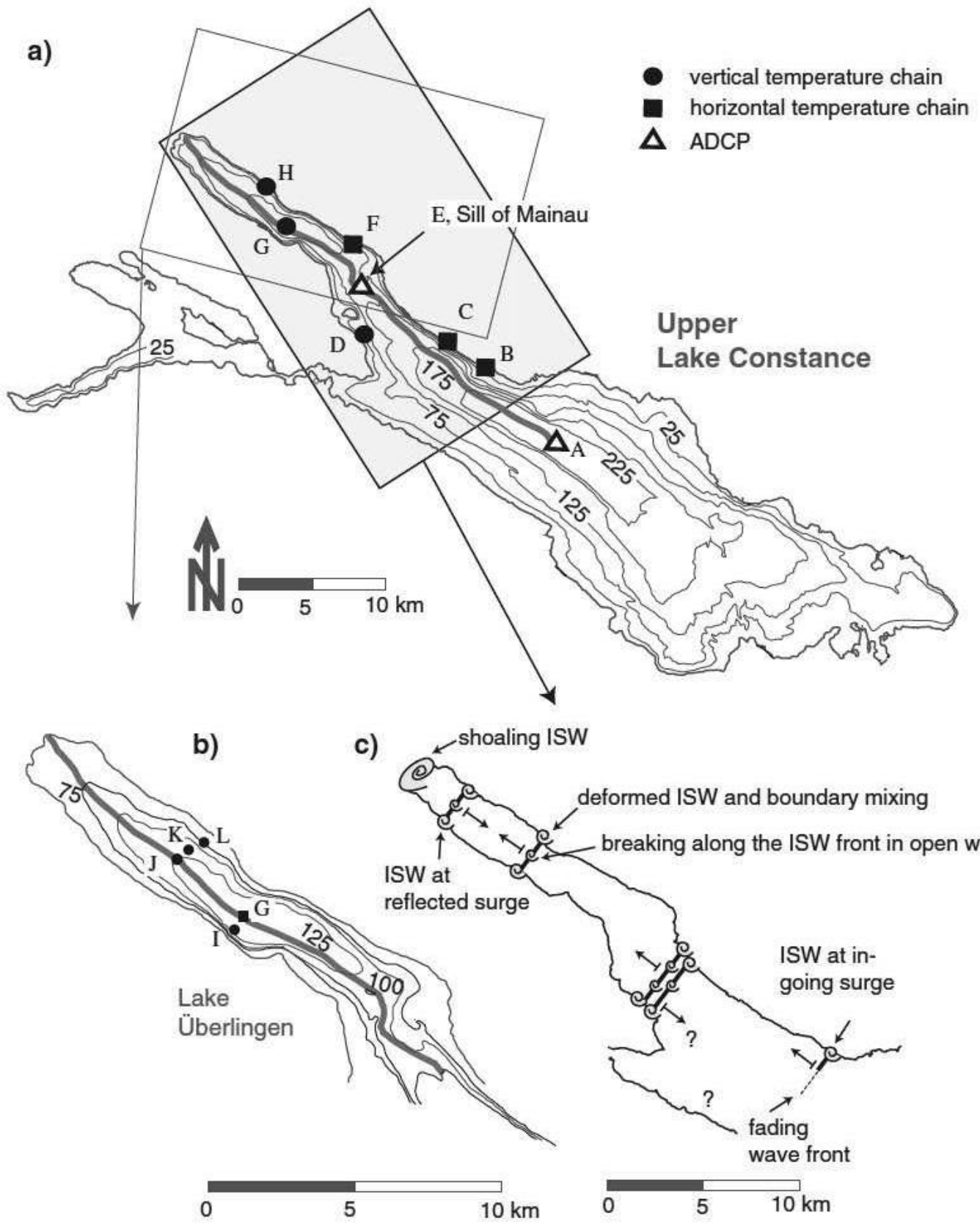

deformed ISW and boundary mixing breaking along the ISW front in open water

Fig. 1 Experimental design and conceptual picture of ISW propagation. a Bathymetry of Upper Lake Constance with the location of the thalweg (grey), moored thermistor chains (black) and ADCPs (white). The study sites during campaign one are labelled A H. b Detailed view of the bathymetry of Lake

$r=\frac{c_{i}}{f}$,

where $f$ is the inertial frequency $\left(f=0.000107 \mathrm{~s}^{-1}\right.$ for Upper Lake Constance) and $c_{i}$ is the phase speed of the
Überlingen with study sites during campaign two (stations G, I) and campaign three (stations J L). c Conceptual picture showing the propagation of an in going and out going surge accompanied by ISWs, including regions of mixing (spiral)

internal wave. The phase speed $c_{i}$ is estimated from Eq. 2 presented below. As a length scale characterizing the basin dimensions we have chosen the mean width of the basins; i.e. $L=2.3 \mathrm{~km}$ for Lake 
Überlingen and $L=9.3 \mathrm{~km}$ for the main basin of Upper Lake Constance.

If the horizontal scale of motion is much larger than the vertical scale, as is the case for basin-scale internal waves, the phase speed $c_{i}$ of these waves can be estimated from the shallow-water equations. Neglecting planetary rotation and assuming that the watercolumn depth $H$ is constant, a normal-mode decomposition of the velocities leads to:

$$
\begin{aligned}
\left(W_{i}\right)_{z z}+\frac{N^{2}(z)}{c_{i}^{2}} W_{i} & =0, \\
W_{i}(0)=W_{i}(H) & =0,
\end{aligned}
$$

where $z$ is the vertical coordinate, $N(z)$ is the BruntVaisälä frequency, the parameters $c_{i}$ are the eigenvalues corresponding to the eigenfunctions $W_{i}(z)$ and $i$ is the mode number. $W_{i}(z)$ describes the $i$ th vertical mode of the vertical velocity and $c_{i}$ is the phase speed of this mode in the horizontal direction. Mode $i=1$ is the fundamental baroclinic mode.

For the water-column depth $H$ we use the mean depth of the lake. Because the hypolimnion of Upper Lake Constance is deep and thick the phase speed of the first vertical mode is not very sensitive to variations in $H$ (Appt et al., 2004). $N(z)$ is calculated from a background temperature profile estimated by averaging temperature profiles measured at 1-min intervals over the 4 days prior to the time of interest; e.g. the time of the passage of the ISWs. The averaging time-span of 4 days was chosen because it corresponds to the mean period of the Kelvin wave during autumn (Bäuerle et al., 1998). From the background temperature profiles, $N(z)$ was calculated using the thermal expansion coefficient for fresh water (Chen \& Millero, 1986). Salinity gradients were neglected in the calculation of $N$ since they are too small to significantly affect stability in Upper Lake Constance. The results for the median, minimum, and maximum internal Rossby radii during the passage of ISWs did not change significantly if either the averaging time was increased or if the fourday mean was centred on the time of interest.

The amplitude and period of the ISWs were estimated by fitting an empirical function for the isothermal depth $\delta_{10}(t)$

$\delta_{10}(t)=10 \mathrm{~m}+A_{10} \operatorname{sech}^{2}\left(\frac{1}{T_{10}}\left(t_{0}-t\right)\right)$ to the observed depth of the isotherm $I_{10}$. The isotherm $I_{10}$ is defined as the isotherm that was located at $10 \mathrm{~m}$ depth before the ISW reached the measuring site. Note that the temperature of the $I_{10}$ isotherm depends on the background stratification. The parameters $A_{10}$ and $T_{10}$ represent the amplitude and period of the displacement of the isotherm $I_{10}$ and were taken here as a measure of the amplitude and period of an ISW. $A_{10}$ describes the maximum vertical displacement induced by an ISW of a water package that was located at $10 \mathrm{~m}$ depth before the passage of the ISW. The parameter $T_{10}$ describes the duration required for the passage of the ISWinduced disturbance of the isotherm $I_{10}$. The parameter $t_{0}$ describes the time of the passage of the solitary wave trough. The isotherm depths were obtained by linear interpolation of the measured temperature profiles made monotonic by reordering to remove local inversions. The parameters $A_{10}, T_{10}$ and $t_{0}$ were obtained by a least squares fit minimizing the difference between $\delta_{10}(t)$ and the measured depth of the isotherm $I_{10}$. The isotherm $I_{10}$ was chosen for the parameter estimation because it is well-resolved at all our measuring stations.

The fitting function (Eq. 3) is motivated by the functional form of the soliton-solution of the $\mathrm{KdV}$ equation for a two-layer system and is similar to the fitting functions used by Moum et al. (2007) and Preusse et al. (2012a). The interpretation of the parameters of the equation applies only to mode-one ISWs of depression. This was the only type of ISW observed at our study sites during all experiments described in the following.

\section{Experiments}

Three field campaigns were conducted to investigate different aspects of ISW propagation. The intention of the first field campaign was to identify the origin of the ISWs and to observe their large-scale propagation along the main axis of Upper Lake Constance from the main basin across the Sill of Mainau to Lake Überlingen, and also within Lake Überlingen (Fig. 1a). The second and third field campaigns were carried out to assess the spatial variation of ISW properties perpendicular to the main propagation direction of the ISWs (Fig. 1b). In the cross-basin direction the properties of the ISWs were compared 
for sites with similar water-column depths (second campaign, stations $\mathrm{G}$ and $\mathrm{I}$ in Fig. 1b) and for sites with different water-column depths (third campaign, stations $\mathbf{J}$ L in Fig. 1b).

In the first campaign, a total of six thermistor chains and two acoustic Doppler current profilers (ADCPs) were moored at different locations in Upper Lake Constance (Fig. 1a). Three thermistor chains were moored vertically with thermistors mounted between 5 and $25 \mathrm{~m}$ water depth (Fig. 1a, solid black circles). The thermistors of the other three chains were deployed perpendicular to the main lake axis from $5 \mathrm{~m}$ down to $25 \mathrm{~m}$ water depth along the sloping bottom, with each thermistor located about $30 \mathrm{~cm}$ above the bottom (Fig. 1a, solid black squares). The vertical spacing of the thermistors was $2 \mathrm{~m}$ between 5 and $25 \mathrm{~m}$ depth in all chains. Temperature data were collected with individual thermistor loggers (TR1050, RBR, accuracy $0.002^{\circ} \mathrm{C}$ ) over 3 months and sampled every $5 \mathrm{~s}$ except at location G (Fig. 1a), where the sampling interval was $60 \mathrm{~s}$ and temperature was measured with a PME thermistor chain (accuracy $0.01^{\circ} \mathrm{C}$ ) almost continuously from 18 February 2009 to 30 November 2010. In addition to the moorings with thermistors, two 600-kHz ADCPs (RD Instruments) were installed, one at the Sill of Mainau and the other at the central station in the main basin of Upper Lake Constance (Fig. 1a, open triangles). The ADCPs were mounted at $50 \mathrm{~m}$ depth looking upwards. The velocity and backscatter profiles covered the range between 50 and $5 \mathrm{~m}$ below the surface with a vertical resolution of $0.5 \mathrm{~m}$. The ADCPs operated in normal mode at a ping rate of $1.08 \mathrm{~Hz}$ and the sampling interval was $30 \mathrm{~s}$ averaging 32 pings.

In the second field campaign, a thermistor chain composed of individual thermistors collected data from 02 June 2010 to 18 September 2010 at station I located south-west of the long-term measuring station $\mathrm{G}$ in Lake Überlingen. The thermistors were mounted vertically between 3 and $25 \mathrm{~m}$ water depth with a spacing of $2 \mathrm{~m}$ and temperatures were sampled every $6 \mathrm{~s}$. The water-column depth at stations $\mathrm{G}$ and $\mathrm{I}$ is $140 \mathrm{~m}$. Note that stations $\mathrm{G}$ and $\mathrm{I}$ are located orthogonally to the thalweg; i.e. the distance between the projected sites G' and I' on the thalweg is zero.

The third field campaign covered the time period from 15 October 2010 to 15 November 2010, when three thermistor chains consisting of individual thermistors were moored at lake depths of 120, 115 and
75 m almost orthogonally to the thalweg (stations J L, Fig. 1a). Temperature was sampled at $1 \mathrm{~Hz}$ at depths between 5 and $60 \mathrm{~m}$ with a spatial resolution ranging from $2 \mathrm{~m}$ in the thermocline up to $10 \mathrm{~m}$ in the deeper water.

\section{Simulation}

In addition to the analysis of the field data with respect to ISWs, the Dubreil Jacotin Long equation in a Boussinesq fluid with water-column depth $H$

$\nabla^{2} \eta+\frac{N^{2}(z-\eta)}{c_{\text {isw }}^{2}} \eta=0$ with $\eta\left(x^{\prime}, 0\right)=\eta\left(x^{\prime}, H\right)=0$,

was solved numerically to determine the phase speed of the ISWs observed during the field campaigns. Here, $\eta=\eta\left(x^{\prime}, z\right)=\eta(x-c t, z)$ is the ISW-induced vertical displacement of the isotherm passing through location $(x, z)$ relative to the isotherm depth at rest. The parameter $c_{\text {isw }}$ is the phase speed of the ISW, $t$ is time and $N(z)$ is the Brunt-Väisälä frequency (Lamb, 2002; Stastna \& Lamb, 2002). The numerical code for solving this equation was provided by M. Stastna and is described in detail in Stastna \& Lamb (2002). The background stratification used to calculate $N(z)$ was determined as a 1-h average of the temperature profiles measured during the time interval from 70 to $10 \mathrm{~min}$ before the passage of the leading ISW of the corresponding wave train at station G, as in Preusse et al. (2012a).

\section{Results}

Basin-scale propagation of ISWs

The temperature data from the three campaigns indicate several events with two consecutive, abrupt descents of the thermocline in Lake Überlingen at station G (Fig. 2a). Similar events have been observed previously by Appt et al. (2004) at a similar location. According to Appt et al. (2004) the first deepening of the thermocline in the centre of Lake Überlingen is caused by the passage of the internal front associated with a surge propagating from the Sill of Mainau towards the western end of Lake Überlingen (in-going surge), whereas a reflected internal front associated 
with the surge propagating in the opposite direction (out-going surge) is responsible for the second deepening of the thermocline.

ISWs usually pass the measuring station shortly before, or together with, the passage of the internal front associated with a surge (Figs. 2a, ISWs and 2b, ISW2, ISW3), which is characterized by a rapid increase in thermocline depth (internal front) followed by a slower decrease in thermocline depth. Wave train ISW2 propagated from station B in the main basin westwards towards station $\mathrm{H}$ (Fig. 3), whereas wave train ISW3 propagated in the opposite direction (Fig. 4). Wave train ISW1 travelled in the same direction as ISW 2 but passed the stations $\sim 9 \mathrm{~h}$ before ISW2 (Fig. 2b); i.e. much earlier than the leading edge of the internal front. However, ISWs without a close connection to a surge appear to be an exception, and we therefore concentrate on ISWs propagating shortly before, or together with, the front of an internal surge. Because of the characteristic shape and the large amplitudes of the ISWs, in all cases, we could clearly identify the leading ISW of the ISW trains.

The number of ISWs in the wave package ISW2 increased along the path of the propagating internal surge from one large ISW at station B to two ISWs at station C, three ISWs at station D and numerous large ISWs at station G (Fig. 3). At the near-shore stations F and $\mathrm{H}$ the shapes of the high-frequency waves in the wave train were deformed, making it difficult to separate out individual solitary waves.

Using a projection of the study sites onto the thalweg (Fig. 1a, grey line), the distance travelled by the leading ISW can be correlated with the time of occurrence of the leading ISW at a particular station (Fig. 4). This allows the phase speed of the leading ISW to be estimated. Phase speeds of the ISWs and of the internal front associated with an internal surge passing after ISW2 (Fig. 2b) are shown in Fig. 4. The times of the passage of the internal front at the various study sites was determined as the time when the
Fig. 2 Progressive surges before and after reflection, together with ISWs

measured at station $\mathrm{G}$ during a the autumn of 2010 and b the summer of 2009. The white arrow indicates the time at which the reflected parts of ISW1 should pass. The leading ISWs of ISW2 and ISW3 (black arrows) and the leading edge of an internal front occur almost at the same time. The end of the internal front is marked (black arrows)

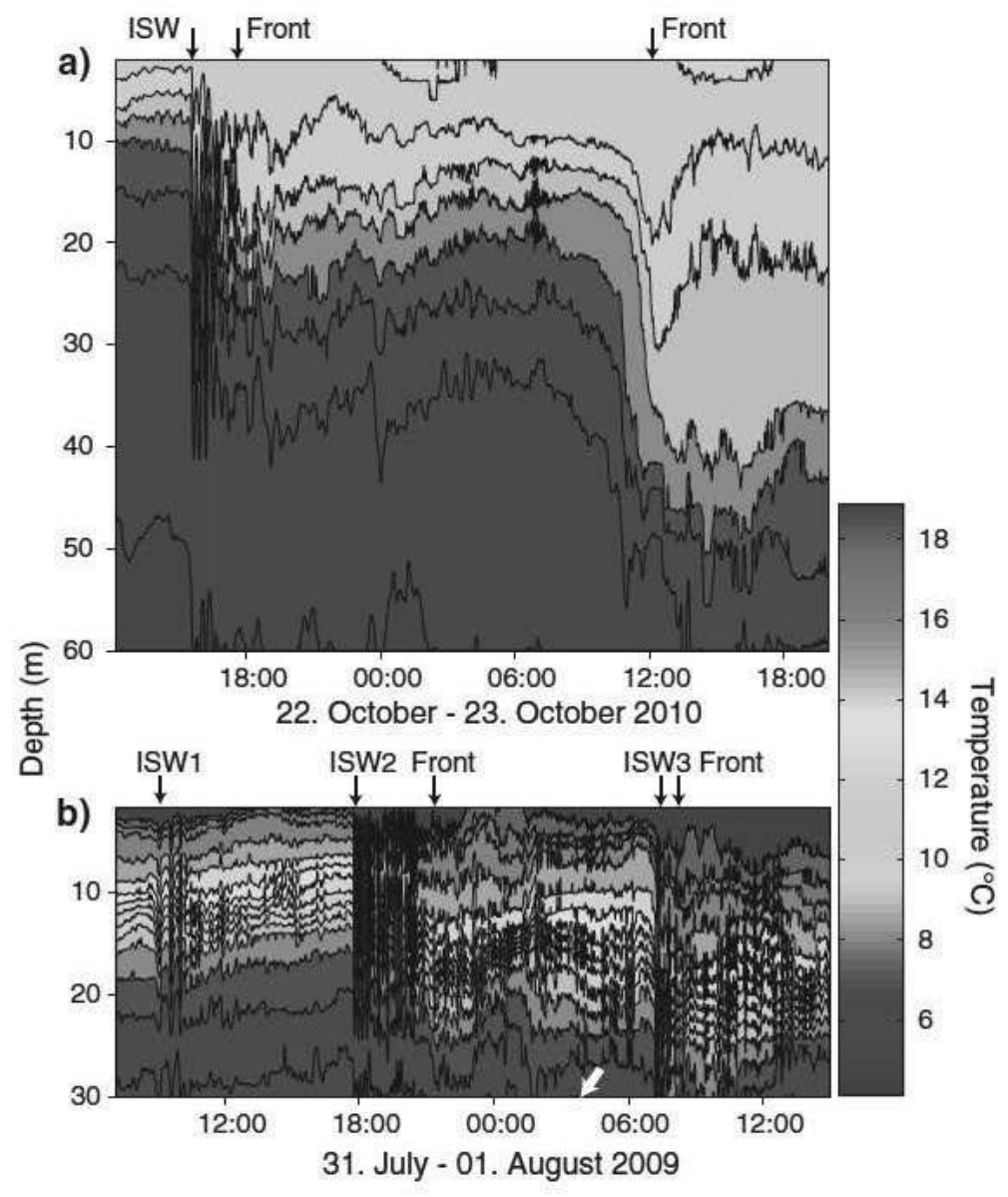




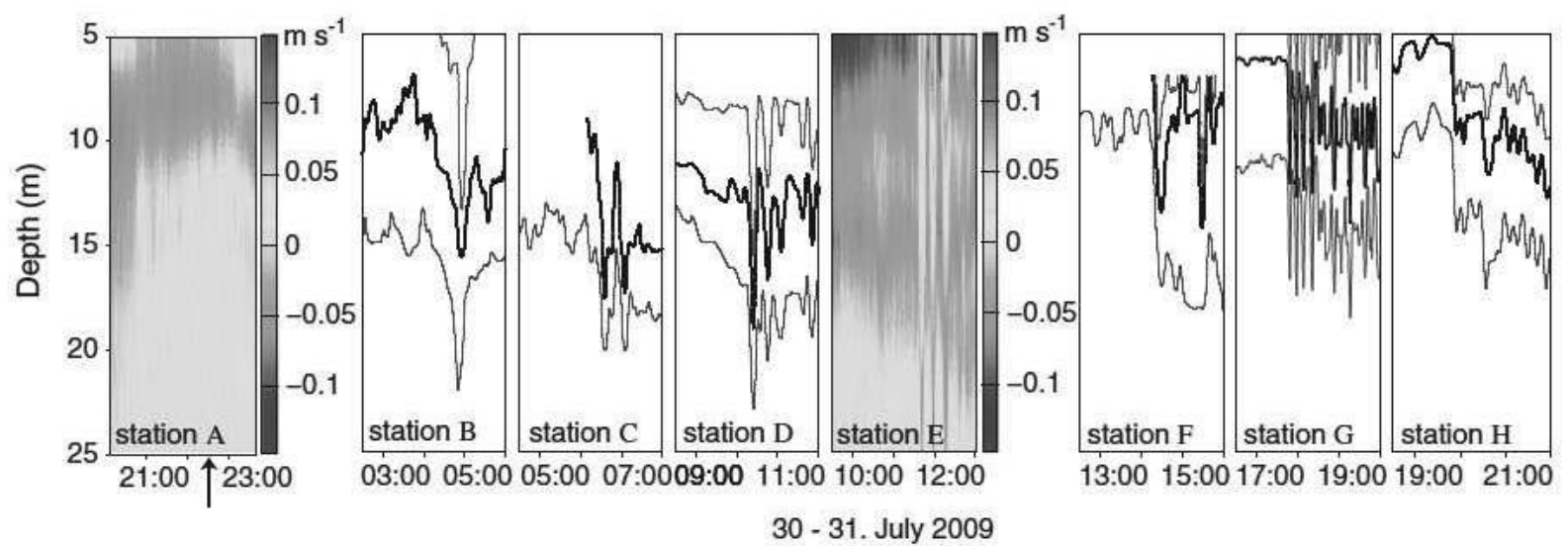

Fig. 3 Evolution of an ISW train along its path from the main basin of Upper Lake Constance to the end of Lake Uberlingen.

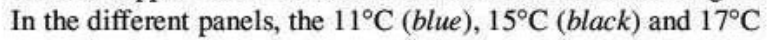
(red) isotherms measured at stations $\mathrm{B} \mathrm{D,F} \mathrm{H}$, and the northward component of the current velocity measured at

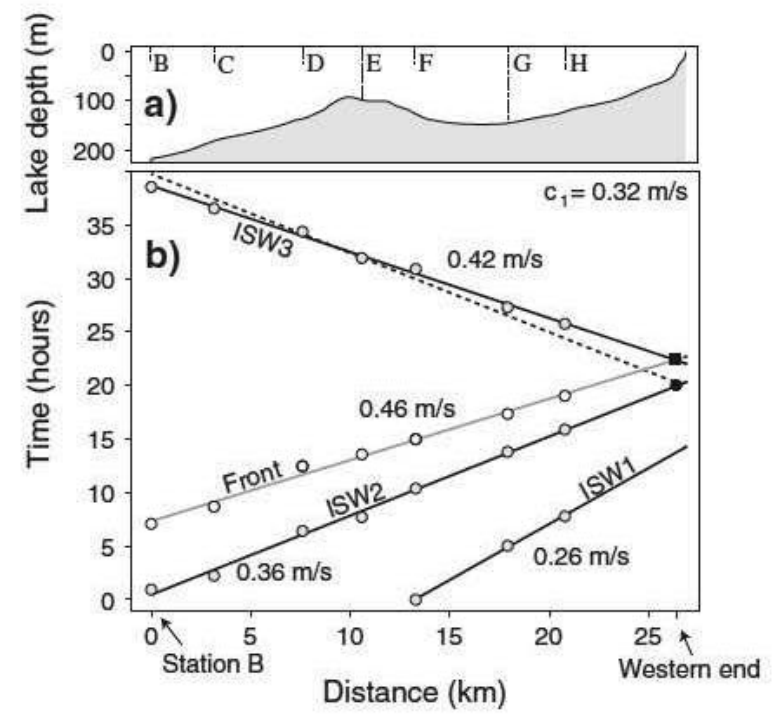

Fig. 4 Propagation path and phase velocities of propagating ISWs and a thermal front on 31 July 2009 and 01 August 2009. a Lake depth at the thalweg. Dotted lines indicate the lake depths at the study sites. Distances refer to a projection of the study sites onto a straight line passing through the thalweg (cf. Fig. 1a). b Times refer to the time lag of the first occurrence of the respective ISW at the various study sites relative to $04: 00 \mathrm{~h}$ on 31 July 2009. The filled dot marks the time at which the waves should have reached the westem end of Lake Uberlingen, and the black square the time at which the front should have been reflected. The dotted line corresponds to the hypothetical path of reflected ISW2, assuming the phase velocity to be maintained after reflection. The timing of the front indicates the timing of the end of the front. It is difficult to pinpoint the leading edge of the internal front, which seems to pass in close temporal proximity to ISW2 stations $\mathrm{A}$ and $\mathrm{E}$, are shown at different times during the day. The $3.5 \mathrm{~h}$ time sections were selected to display the leading solitary waves, where the possible time for the occurrence of the ISWs at station A (arrow) was extrapolated by assuming a linear phase velocity. The locations of the stations are shown in Fig. 1a

lowpass-filtered (Butterworth filter, cut-off frequency $30 \mathrm{~min}$ ) thermocline depth reached a maximum between the occurrence of ISW2 and ISW3. This time corresponds to the passage of the end of the internal front, and was determined more reliably than, for instance, the timing of the fastest change in thermocline depth associated with the internal front. At station $\mathrm{E}$ the timing of the internal front was determined as the time of the reversal in water velocities after the passage of ISW2. According to Fig. 4, the phase speed of the ISWs appears to be independent of the varying water depth even when the waves travel from the main basin of Upper Lake Constance to Lake Überlingen across the Mainau Sill (Fig. 4a, b, ISW2, note the positive slope of the pathtime function).

The reflection or shoaling of the ISWs and the surge takes place at the location where the thermocline intersects with the sloping boundary of the western end of Lake Überlingen (Fig. 4b, filled square and circle). The phase speeds of the leading ISW of ISW2 and ISW 3 determined from the linear regression of the path-time function are $c_{\text {isw }}=0.36 \mathrm{~m} / \mathrm{s}$ and $c_{\text {isw }}=$ $0.42 \mathrm{~m} / \mathrm{s}$, respectively. The phase speeds of these ISWs calculated from the DJL equation using the amplitude of the leading ISWs observed at station G agree with the values obtained from the path-time analysis. The ISWs of ISW1, which have a smaller amplitude than those of ISW2, propagated at a phase speed of only $0.26 \mathrm{~m} / \mathrm{s}$, and thus were much slower 
than the ISWs associated with the surge. The phase speed of the fundamental mode basin-scale internal wave estimated from Eq. 2 was $c_{1}=0.32 \mathrm{~m} / \mathrm{s}$, which is similar to the phase speed of the ISW2 associated with the in-going surge, but less than the phase speed of $0.46 \mathrm{~m} / \mathrm{s}$ of the in-going internal front estimated from the regression of the path-time relationship. However, the path-time relationship may result in an overestimate of the phase speed of the internal front: as the front of the propagating surge steepens, its trailing end, which was used to define the position of the front, propagates faster than the leading edge of the front.

\section{Fate of ISWs}

Reflected surges are often accompanied by ISWs, but not always (Fig. 2a, third arrow). An example of ISWs associated with the internal front of a reflected surge (out-going ISWs) is shown in Fig. 2b (ISW3). The reflected front is steeper than the in-going front and does not extend much beyond ISW3 (Fig. 2b). Compared with the ISWs of wave train ISW2 propagating together with the in-going surge (in-going ISWs, Fig. 2b, ISW2), the number of out-going ISWs in wave train ISW3 is reduced. Assuming that incident and reflected ISWs have the same phase speed, the return-time and the hypothetical path of reflected ISWs can be estimated from the phase speed of the incident ISWs. The ISWs of ISW1 observed during campaign one clearly did not return from the western end of Lake Überlingen at the expected time estimated from their phase speed (marked by the white arrow in Fig. 2b). The occurrence of the eastward propagating ISW3 at stations $\mathrm{H}$ is delayed by $\sim 1 \mathrm{~h}$ compared to the time of occurrence expected for reflected waves of the incident wave train ISW2 (Fig. 4b: circles correspond to out-going ISW3 and the dashed line to the hypothetical path of reflected waves from wave train ISW2). The time of occurrence of ISW3 at the terminal boundary at the western end of Lake Überlingen estimated from the phase velocity of ISW3 (Fig. 4b, black square) coincides with the estimated time of reflection of the internal front associated with the in-going surge, but was $\sim 2 \mathrm{~h}$ later than the expected arrival of ISW2 at this location (Fig. 4b, black circle).

During field campaign two, the out-going wave trains contained fewer ISWs than the corresponding in-going wave trains (Fig. 5). The propagation direction along the thalweg of the wave trains was determined from the time lag between successive ISW trains passing station $G$ in combination with the observation of either the first (in-going ISWs) or the second (out-going ISWs) abrupt descent of the thermocline as demonstrated in Fig. 2. The same procedure to identify the propagation direction of ISWs was employed in Preusse et al. (2012a). During campaign two, 14 in-going wave trains, but only nine out-going wave trains, were observed at station $\mathrm{G}$ and at station I. During campaign three, all three ISW trains propagated towards the western boundary of Lake Überlingen and did not return (one of the ISW trains is depicted in Fig. 2a).

\section{Width and orientation of ISW fronts}

The trough of the leading ISW (termed the ISW front in the following) appears to have been extended over the total width of Lake Überlingen, since the waves were observed at both boundaries of the lake (stations $\mathrm{D}, \mathrm{F}, \mathrm{H}$ ) as well as at the lake's centre (stations E and G) (Fig. 4). In our experiments, the internal Rossby radius $r$ of the fundamental mode basin-scale linear internal wave typically ranged from $2100 \mathrm{~m}$ to 3086 m (Fig. 6), whereby a smaller $r$ was obtained for the weaker stratification at the beginning of June during field experiment two (Fig. 6, crosses). During most of the time, $r$ exceeded the mean width of Lake Überlingen $(2300 \mathrm{~m})$, suggesting that the Earth's rotation should not cause a substantial decline in the amplitude of the basin-scale internal wave across the basin width, and the amplitude of the internal front associated with the wave should thus not vary much in the cross-propagation direction.

In the central part of the main basin of Upper Lake Constance, however, the distance to shore can be several times greater than $r$. For example, the distance between Station A in campaign one (Fig. 1a, triangle) and the lake shore was approximately $7 \mathrm{~km}$. Hence, the amplitude of the internal front associated with the surge can be expected to be much smaller at station A than close to the shore, making the generation of ISWs at a steepening surge less likely at station A than at near-shore locations. We consistently did not observe any indication of ISWs in the current velocity or backscatter signal at station A (Fig. 3). Note that according to the DJL equation (Eq. 4) applied for the measured stratification, the maximum horizontal 


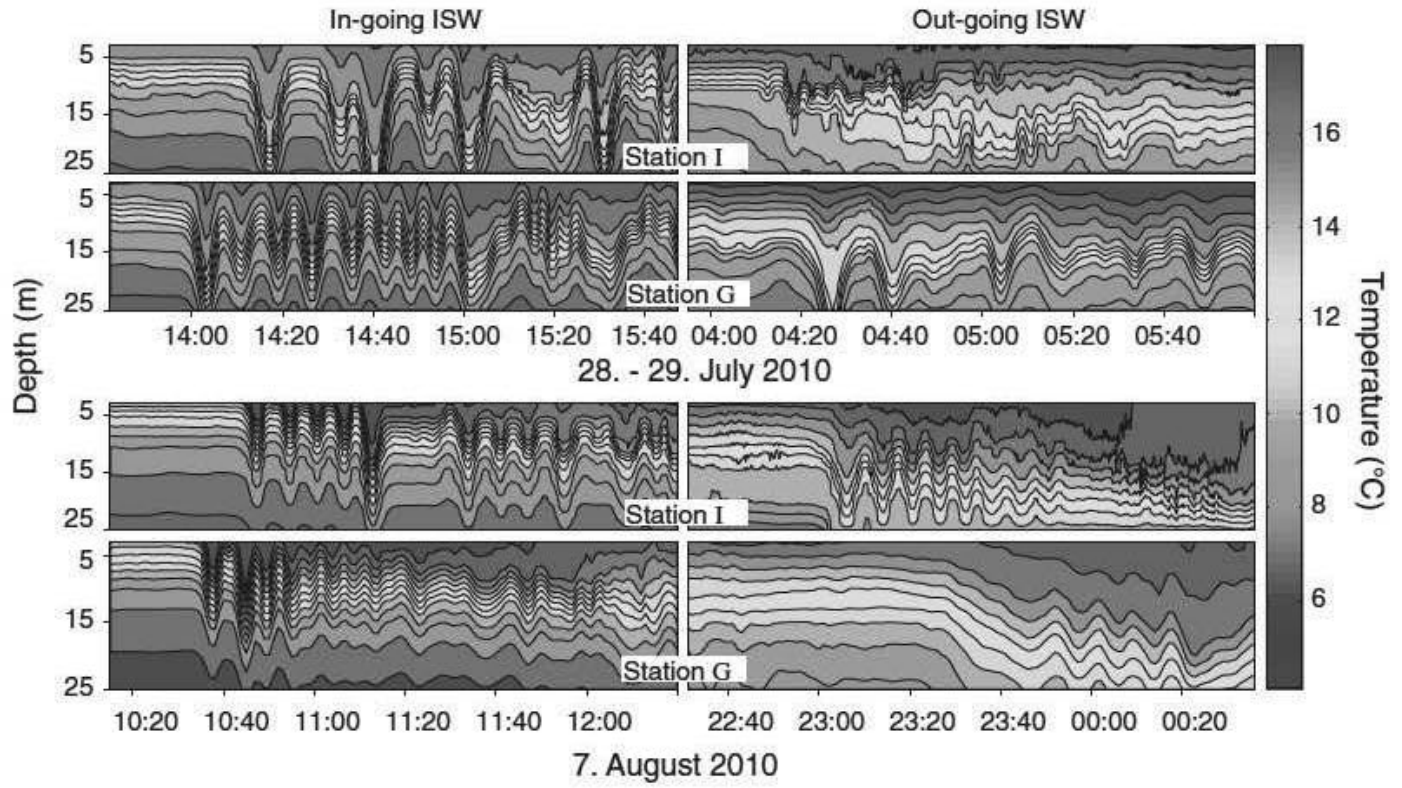

Fig. 5 Temperature data showing in going and out going ISW trains measured at the central station G and at the station I close to the southern boundary of Lake Überlingen on 28 and 29 July 2010 and on 07 August 2010

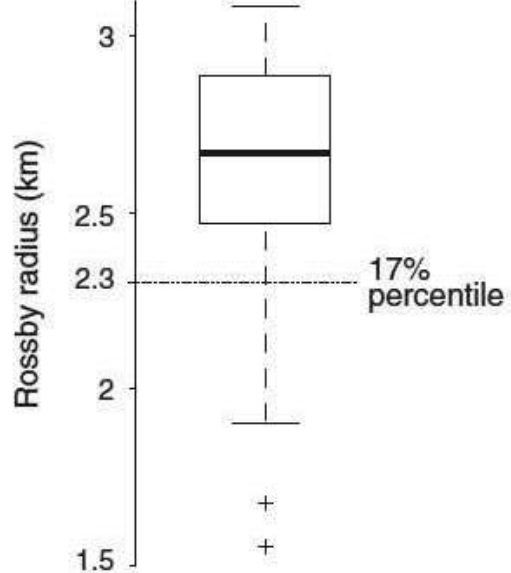

Fig. 6 Statistical properties of the Rossby radius measured during the passage of ISWs in all three field experiments. $83 \%$ of the ISWs propagated in stratifications that imply an internal Rossby radius $r$ exceeding the mean width of Lake Überlingen $(2.3 \mathrm{~km})$ (dotted line: in $17 \%$ of the cases, $r$ lies below this line). Note that the width of the central basin $(14 \mathrm{~km})$ is substantially greater than the Rossby radius associated with the ISWs. The outliers (crosses) correspond to the Rossby radius associated with in going and out going ISWs propagating in the weak stratification during the beginning of June

current velocities associated with ISWs with amplitudes $>3 \mathrm{~m}$ should exceed $0.1 \mathrm{~m} / \mathrm{s}$. Such a strong, high-frequency signal would clearly be visible in the current velocity data (e.g. Fig. 3, station E), but was not observed at station A.

During field campaigns two (Figs. 5, 7) and three (Fig. 8), ISWs belonging to the same internal front appeared at the stations located almost in the crosspropagation direction within time intervals of less than 40 and $28 \mathrm{~min}$, respectively. More than 20 ISW trains that were measured at station $\mathrm{G}$ in the centre of Lake Überlingen during field campaign two were also observed at station I, indicating that the ISW front extended at least from the centre to the southern boundary of the basin. On average the leading ISW of the in-going wave train reached station G $14 \mathrm{~min}$ earlier than it reached station I, whereas the leading ISW of the out-going wave train occurred on average 22 min later at station $\mathrm{G}$ than at station I.

Quantitative comparison of the wave properties of ISWs observed at stations G and I (Fig. 9) shows no significant difference of amplitude and period ratios between in-going and out-going ISWs (Kruskal Wallis test, $P>0.05$ ). The median ratio of the amplitudes, and also of the periods, of in-going and out-going ISWs were similar (Fig. 9), indicating that, orthogonal to the thalweg within the distance between stations G and I, the properties of ISWs in particular their amplitudes did not change significantly. 


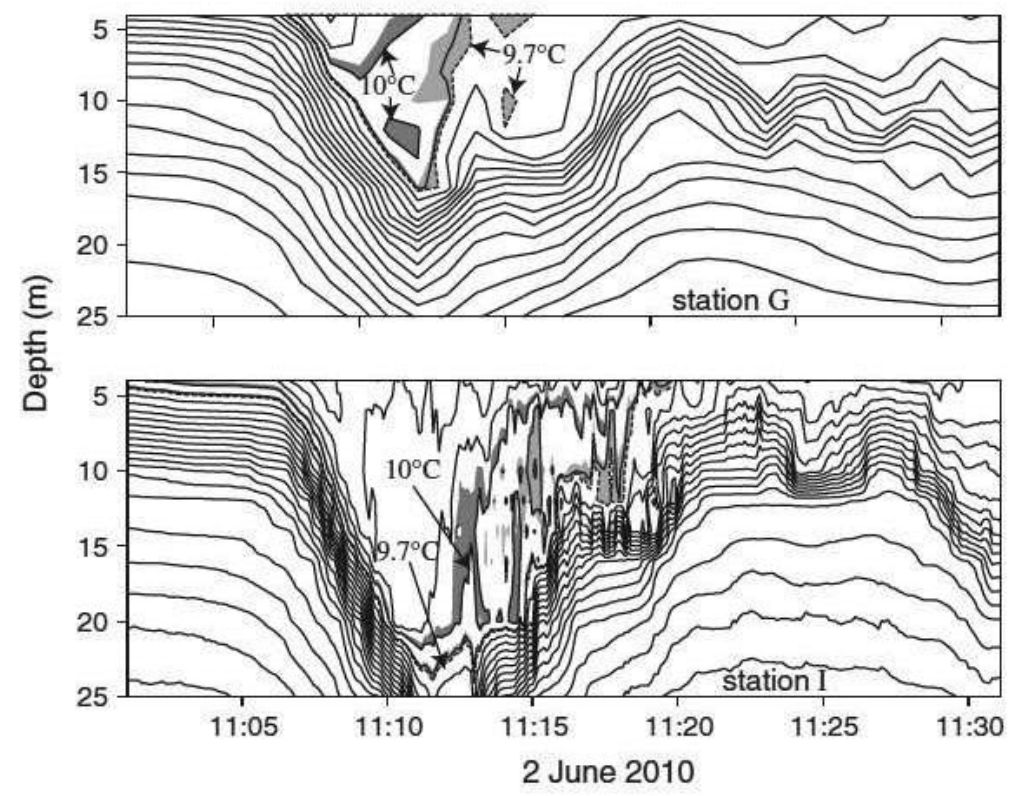

Fig. 7 Temperature data showing a breaking ISW measured at the central station $\mathrm{G}$ and at the station I close to the southern boundary of Lake Uberlingen in June 2010. Isotherms are given in intervals of $0.25^{\circ} \mathrm{C}$. The shaded areas represent temperatures from 9.7 to $9.8^{\circ} \mathrm{C}$ (blue) and from 10.0 to $10.1^{\circ} \mathrm{C}$ (red), and the dotted line corresponds to the $9.7^{\circ} \mathrm{C}$ isotherm. The time axis in
Fig. Tb has the same scaling as in Fig. 7a but is shifted by $39 \mathrm{~min}$ to align the passage of the isotherm displacements at stations $\mathrm{G}$ and I that belong to the same ISW front (red). Note that the sampling rates at station $\mathrm{G}$ and station I were different ( $1 \mathrm{~min}$ and $6 \mathrm{~s}$, respectively)

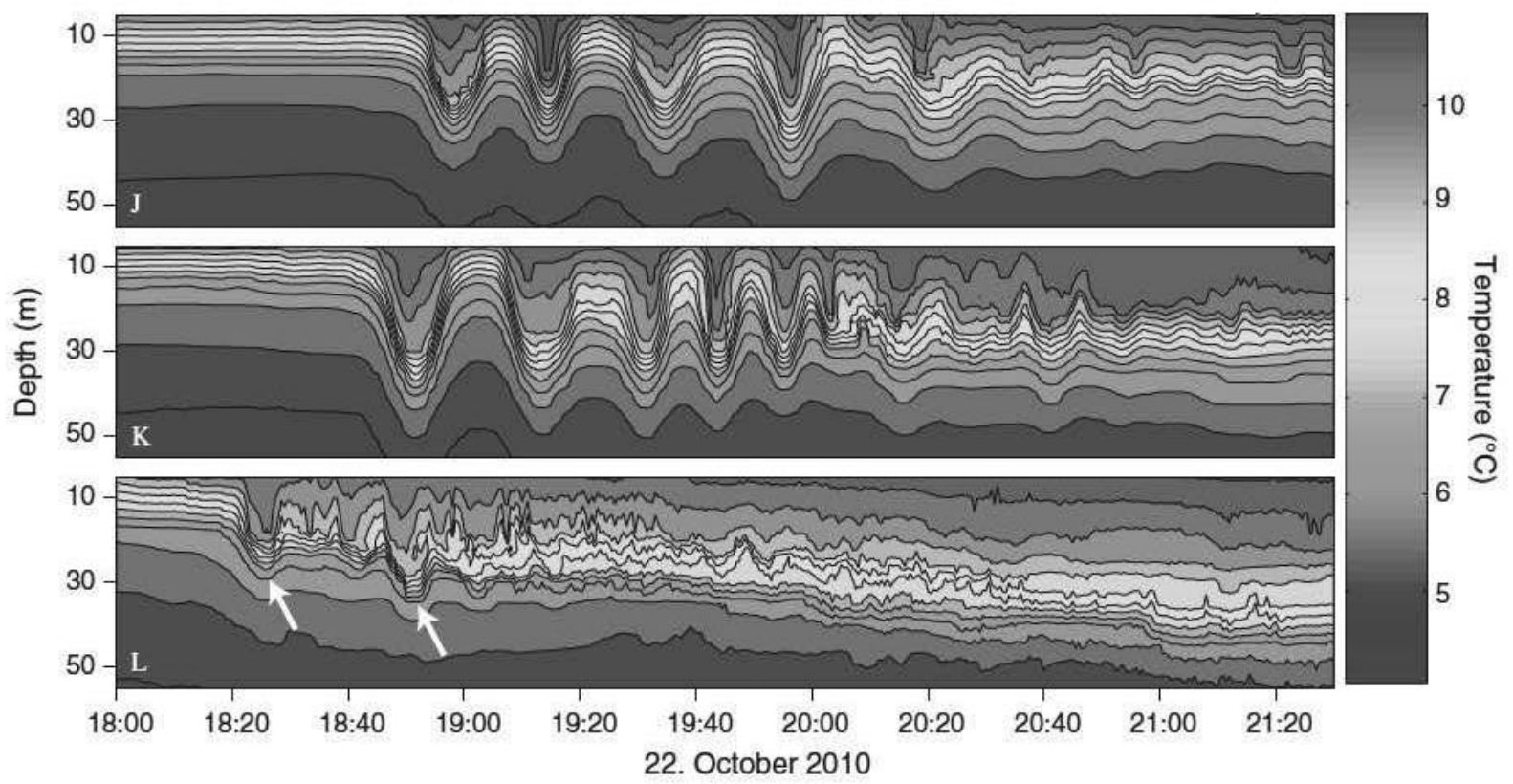

Fig. 8 Temperature data, showing ISWs measured simulta neously at stations $\mathrm{J} \mathrm{L}$, demonstrating the influence of lake depth on the wave front. Certain ISWs observed at the boundary station $\mathrm{L}$ are marked by white arrows. Temperature inversions are visible in the bottom panel; e.g. above the second arrow at $\sim 20 \mathrm{~m}$ depth 


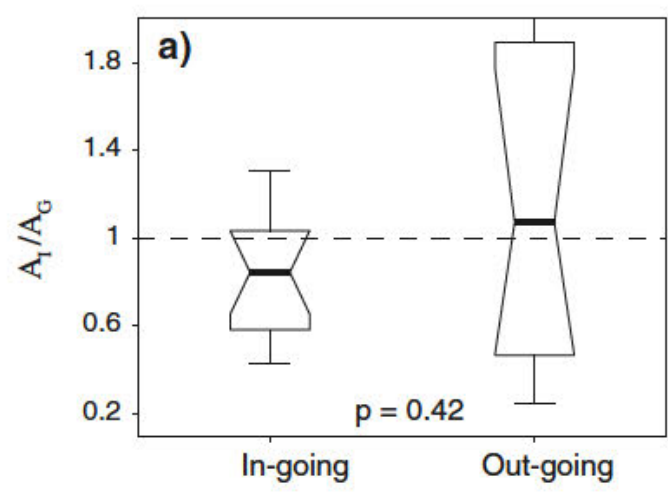

Fig. 9 Statistical comparison of wave properties of in going and out going ISWs passing the two stations $\mathrm{G}$ and I, which were located at similar lake depths. a Ratio $A_{\mathrm{I}} / A_{\mathrm{G}}$ of amplitudes A. b Ratio $T_{\mathrm{I}} / T_{\mathrm{G}}$ of periods $T$ of ISWs measured at stations I and

During campaign one, the correlation coefficients between the times of the passage of the ISWs and the distance travelled by them along the thalweg (Fig. 4b, ISW2 and ISW3) are significant (Student's $t$ test, $P<0.01$ ) and explain $99 \%$ of the observed variance. As the measuring stations are positioned not only at open-water sites close to the thalweg, but also at shore sites, the good correlation suggests that the propagation direction of the ISW front is roughly parallel to the thalweg. However, the time of occurrence of ISWs expected under the assumption that the ISW front is orthogonal to the thalweg does not agree exactly with the observed time of occurrence of ISWs at openwater and near-shore stations. This deviation in the timing of the ISWs suggests a bending of the ISW front in cross-propagation direction towards the boundaries. This was investigated in more detail based on the observations from the stations aligned almost perpendicular to the thalweg; i.e. stations $\mathrm{G}$ and I (e.g. Figs. 5, 7) and stations J, K, and L (e.g. Fig. 8).

The bending angle of the ISW front between the thalweg and the southern shore of Lake Überlingen was estimated from the phase speed of the ISWs calculated with the DJL equation using the amplitudes observed at station $\mathrm{G}$ under the assumption that the phase velocity was constant along the ISW front. Comparison of the time delay between the passage of the ISWs through stations $\mathrm{G}$ and I with the expected arrival times from the simulated phase velocities provides the bending angle $\phi$ of the front (defined in Fig. 10a). Between stations G and I the front of in-going and out-going ISWs has a median bending angle $\phi$ of $\sim 30^{\circ}$ and $\sim 40^{\circ}$, respectively (Fig. 10a).

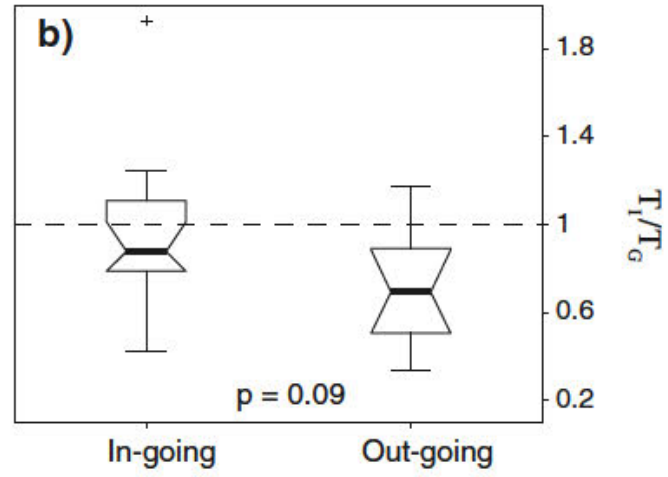

G. Amplitudes and periods were calculated from the isotherm that is at rest in $10 \mathrm{~m}$ depth shortly before the passage of the corresponding ISW by fitting the isotherm to the function $10 \mathrm{~m}+A_{10} \operatorname{sech}^{2}\left[\left(t_{0} \quad t\right) / T_{10}\right]$ (Eq. 3)

Because in-going waves typically reach station $\mathrm{G}$ first, whereas out-going waves appear first at station $I$, the bending of the front relative to the orthogonal to the thalweg is typically in the same direction for in-going and out-going ISWs (Fig. 10b).

The bending of the ISW front is not necessarily linear, and was observed to vary with distance to the thalweg in campaign three (Fig. 10c). The leading ISW belonging to the same ISW train occurred at stations $\mathbf{J}$ and $\mathrm{K}$ within $6 \mathrm{~min}$ (Fig. 8). With the phase velocity of $0.26 \mathrm{~m} / \mathrm{s}$ determined from the DJL the bending angle of the ISW front was approximately $1^{\circ}$ between stations $\mathrm{J}$ and $\mathrm{K}$; i.e. the orientation of the ISW front was almost orthogonal to the thalweg. The leading ISW, however, occurred approximately 28 min earlier at station $\mathrm{L}$ than at station $\mathrm{K}$. The bending of the ISW front between stations $\mathrm{K}$ and $\mathrm{L}$ was thus larger than between stations $\mathrm{J}$ and $\mathrm{K}$; i.e. $\phi=18^{\circ}$ (same definition of $\phi$ as in Fig. 10a), suggesting a forward-bending of the ISW front towards the northern shore. Note, however, that during the passage of three different ISW trains during campaign three, both forward- and backward-bending was observed between stations $\mathrm{K}$ and $\mathrm{L}$, whereas the orientation of the bending hardly changed for the ISW fronts observed between stations $\mathrm{G}$ and I during campaign two.

\section{Spatial variation of ISW properties}

Comparison of the ISWs observed at stations G and I (Figs. 5, 9) indicates that ISWs propagating in regions with similar water depths and stratification, separated by a distance less than one half of the Rossby radius, 


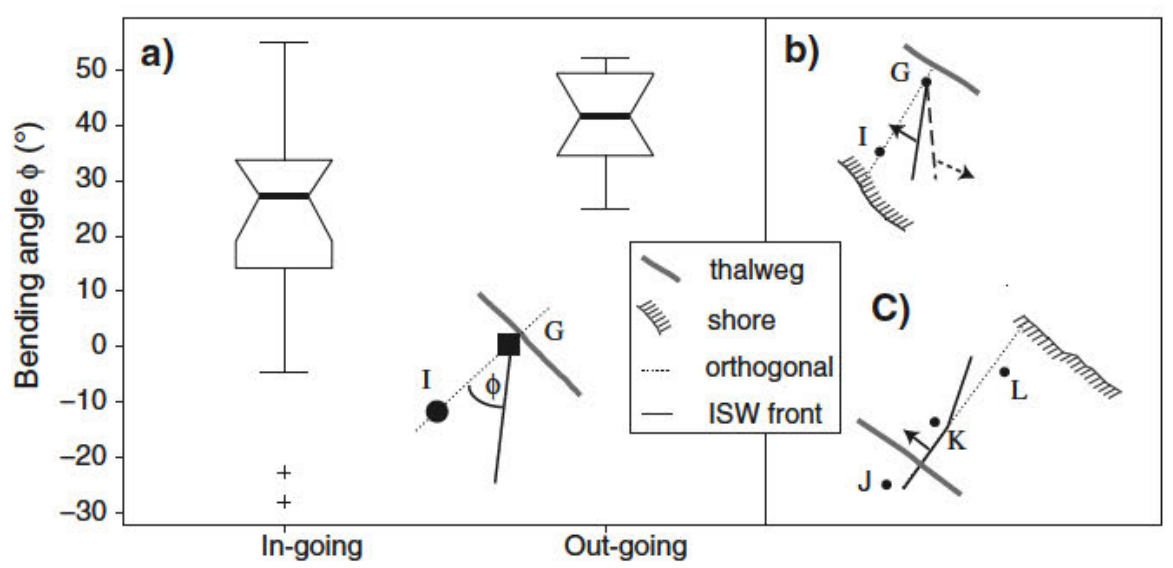

Fig. 10 Bending of the ISW front. The phase velocities of the wave fronts were determined from the DJL equation using the amplitudes observed at station G. a Statistical comparison of the bending angle $\phi$ of in going and out going ISW fronts passing the two stations $\mathrm{G}$ and $\mathrm{I}$, which were located at similar lake depths. The angle $\phi$ is defined in the sketch. Compared to the

have similar properties. The similarity of the wave properties holds not only for the amplitudes of the leading ISWs (Fig. 9) but also for the occurrence of temperature inversions associated with the ISWs (Fig. 7). Temperature inversions, considered to be evidence of wave breaking (Thorpe, 1977; Alford \& Pinkel, 2000; Preusse et al., 2010, 2012a, b), are indicated by areas with closed isotherms in Fig. 7a, b. During the passage of the ISW at the central station G in Lake Überlingen (Fig. 7a), temperature inversions of up to $0.2^{\circ} \mathrm{C}$ occurred between 10 and $15 \mathrm{~m}$ in four profiles, and in one case extended over more than two thermistors covering $4 \mathrm{~m}$ water depth. At the nearshore station I, numerous overturns are visible (Fig. 7b) for the same ISW front observed at station $\mathrm{G}$ (Fig. 7a). The structure of the overturns is resolved in more detail at station I than at station $\mathrm{G}$ because of the higher temporal resolution of the measurements at station I. Note that the time axis in Fig. $7 \mathrm{~b}$ has the same scale as in Fig. 7a, but is shifted by $39 \mathrm{~min}$ to align the passage of the isotherm displacements at stations $\mathrm{G}$ and I that belong to the same ISW front. At both stations the breaking process causes inversions in the same temperature range [shaded areas represent temperatures from 9.7 to $9.8^{\circ} \mathrm{C}$ (blue) and from 10 to $10.1^{\circ} \mathrm{C}$ (red)] and parts of the fine structure of the wave motion; e.g. the upward motion of the $\sim 10.1^{\circ} \mathrm{C}$ water at station $\mathrm{I}$ (Fig. 7b) and that of the $\sim 9.8^{\circ} \mathrm{C}$ water at station $\mathrm{G}$ (Fig. 7a) look rather similar. orthogonal direction to the thalweg, in going waves are bent backwards towards the southern shore, whereas out going waves are bent forward. b Median bending of the in going (solid line) and out going (broken line) ISW fronts passing G and I. c Bending of the ISW front observed on 22 October 2010, passing stations $\mathbf{J} \mathbf{L}$

The ISW train observed at the shallow-water station L near the lake boundary (Fig. 8) has a very different structure to that of the ISW train observed at the deepwater stations $\mathrm{J}$ and $\mathrm{K}$. Individual ISWs passing station $\mathrm{L}$ are more difficult to distinguish than at $\mathrm{J}$ and $\mathrm{K}$, as several additional coherent vertical displacements of isotherms that could also be ISWs appear with close temporal spacing. The leading two ISWs visible at stations $\mathrm{J}$ and $\mathrm{K}$ may be the two largest features at station $\mathrm{L}$ indicated by the arrows in Fig. 8. The amplitudes of the ISWs at the shallow, near-shore station are strongly diminished compared to the amplitudes of the ISWs at the deep-water stations further away from the bottom boundary. The ISWs at station $\mathrm{L}$ are associated with several temperature inversions with a large overturn visible above the second arrow at $\sim 20 \mathrm{~m}$ depth, suggesting that wave breaking contributes to the decline in amplitude towards the shallower boundary station $\mathrm{L}$.

\section{Discussion}

\section{Origin of the ISWs}

Internal solitary waves were observed during the three campaigns at all measuring stations except at station A, confirming that ISWs are common in stratified lakes and not limited to very localized regions. ISWs apparently occur even in the central basin of Upper 
Lake Constance (Fig. 3, stations B D), indicating that the generation of ISWs is not restricted to the Sill of Mainau. ISWs do not occur at station A in the central part of the main basin, where, as a result of the Coriolis effect, the amplitude of north-westward propagating basin-scale internal waves is substantially reduced compared to locations near the northern shore. ISWs observed near the northern shore of the main basin (Fig. 3, stations B and C) were associated with the front of an internal surge. These observations suggest that the progressive non-linear surge is a main source of ISW2 observed during campaign one, propagating from the main basin into Lake Überlingen (Figs. 3, 4). Topographical effects, however, may enhance the nonlinear steepening of internal surges, thus supporting the generation of ISWs (Dorostkar \& Boegman, 2013). Such a topographical effect is suggested by the larger number of ISWs observed at station $G$ in the centre of Lake Überlingen after the surge had passed the Sill of Mainau, compared to the number of ISWs in the main basin of Upper Lake Constance (Fig. 3).

In Lake Überlingen, not only ISW2, but also additional trains of solitary waves were observed: ISW1 propagating in the same direction as ISW2, and ISW3 propagating in the opposite direction. The ISWs of ISW1 passed the stations in Lake Überlingen much earlier than ISWS2 and the internal front associated with ISW2 (Fig. 4). As the phase speed of ISW1 is $\sim 0.26 \mathrm{~cm} / \mathrm{s}$, the time differences between the occurrences imply that ISW1 waves travelled $\sim 11 \mathrm{~km}$ ahead of the end of the leading edge of the internal front and $\sim 8 \mathrm{~km}$ ahead of it, suggesting that ISW1 waves did not originate from the same surge as ISW2 waves.

The ISWs of wave train ISW3 are either reflected ISWs of wave train ISW2 or newly produced ISWs during the reflection process of the surge and the subsequent steepening of the eastwards propagating internal front. The latter processes would appear to be the more likely origin of ISW3 than the former, as the calculated timing of the occurrence of the leading ISW of ISW3 at the reflection point agrees much better with the arrival time of the internal front associated with the in-going surge than with the arrival time of the leading ISW of ISW2.

\section{Breaking of ISWs at the boundaries}

Neither wave train ISW1 nor any of the ISWs observed during campaign three propagating towards the western terminal boundary of Lake Überlingen returned. During campaign two several of the in-going ISWs also did not return, and the out-going wave trains associated with the returning front contained a smaller number of ISWs and had a different shape than the ingoing wave trains (Fig. 5). These observations suggest that ISWs break at the sloping boundary at the western end of Lake Überlingen and release energy to higherfrequency processes, which is consistent with laboratory experiments (Boegman et al., 2005), numerical simulations (Lamb \& Nguyen, 2009; Aghsaee et al., 2010) and field measurements in the ocean (e.g. Moum et al, 2007). The fate of the ISWs propagating from Lake Überlingen into the main basin is still unknown. If these waves maintain their energy in the main basin and propagate eastwards, they too could release their energy at the eastern end of the lake in a similar way as the westward propagating ISWs release their energy at the western end of Lake Überlingen.

In comparison to the well-shaped ISWs of solitary wave trains observed in the open water, the ISWs at boundary stations in shallower waters are often deformed and have smaller amplitudes (e.g. Fig. 8). The decrease in the amplitudes of ISWs along the same ISW front towards boundary stations at shallower water depth may result from the breaking of the ISWs in the shallower water near the boundaries, as suggested by temperature inversions connected with the occurrence of ISWs; e.g. at station L in campaign three (Fig. 8).

Earlier studies have demonstrated that ISWs break at near-shore sites in Upper Lake Constance and that the breaking is associated with a substantial increase in turbulent kinetic energy in the bottom boundary layer (Lorke, 2007, measuring near station D) and in the thermocline (Preusse et al., 2010, measuring near station H). Because ISWs occurred at all our stations except station $\mathrm{A}$, enhanced turbulence in the bottom boundary layer resulting from breaking ISWs can be expected all around Lake Überlingen, and also at the northern shore of the main basin of Upper Lake Constance. Our observations suggest that the contribution of boundary mixing from the breaking of ISW's to overall mixing is probably larger in Lake Überlingen than in the main basin of Upper Lake Constance because of the higher number of large ISWs in the wave trains in Lake Überlingen.

The increased turbulent viscosity resulting from wave breaking in shallow waters may be one reason 
for the bending of the solitary wave front. Spatial variation in basin morphometry and refraction resulting from changes in phase speed with a decline in wave amplitude and water depth may also contribute to the bending of the ISW front. However, observations with better spatial resolution would be required to explain the bending of the ISW front, and especially of the bending of the in-going and out-going ISW fronts between stations $\mathrm{G}$ and I, where the properties of the ISWs, water depth, and stratification are very similar along the fronts.

\section{Breaking of ISWs in the open water}

Temperature inversions associated with ISWs indicating wave breaking were observed not only at shallower water stations but also in the deep, open water at the central station $\mathrm{G}$ in Lake Überlingen (e.g. Fig. 7). This observation is consistent with an analysis of 6 years of observations from station $G$, demonstrating that the leading ISW of more than 200 ISW trains at station $\mathrm{G}$ had an amplitude $>3 \mathrm{~m}$ and that more than $15 \%$ of these ISWs were accompanied by temperature inversions (Preusse et al., 2012a). Numerical simulations with the DJL equation confirmed that the ISWs associated with temperature inversions had the characteristics required for breaking, and that $50 \%$ of these ISWs broke as a result of shear instabilities and the other half as a result of convective instabilities (Preusse et al., 2012b). A simulation of the ISW shown in Fig. $7 \mathrm{a}$ with the DJL equation indicates that the amplitude of this wave is above the critical limit for wave breaking (for details on the critical limit for wave breaking see Lamb, 2002; Stastna \& Lamb, 2002) and that breaking should result from convective instability.

Breaking of ISWs in the interior of deep lakes depends mainly on the stratification and on the amplitude of the ISW (Lamb, 2002; Stastna \& Lamb, 2002). At locations with similar water depth separated by distances of less than half the internal Rossby radius, the properties of ISWs, including their amplitudes, do not vary much along an ISW front (Fig. 9). Hence, if ISWs become sufficiently large so that they break at the prevailing stratification, breaking can be expected to occur not only locally, but along the ISW front. This is supported by the observation of temperature inversions associated with the passage of the same ISW front at stations G and I (Fig. 7a, b), which are located at about the same position along the thalweg but separated in the cross-basin direction.

\section{Implications}

Wave breaking results in vertical mixing, and consequently in a vertical flux of plankton and nutrients. If breaking occurs along the ISW front, as is suggested by the observations above, strips of increased mixing, and thus of vertical fluxes of plankton and nutrients, extend over the entire basin width of Lake Überlingen and propagate through the basin at the phase speed of the ISWs. As nutrients and plankton show strong vertical gradients during the stratified period, strips of increased vertical transport may result in horizontally heterogeneous growth conditions and phytoplankton abundances, and thus may contribute to the generation of plankton patchiness.

Besides mixing, advective transport resulting from internal waves is important in stratified lakes. Highfrequency internal waves vertically displace neutrally buoyant particles over several metres within a few minutes (Huber et al., 2011). Our observations suggest that such vertical motion induced by ISWs, causing light and pressure stress on phytoplankton at short time scales, occur regularly at many locations, and especially in Lake Überlingen. ISWs have the potential to transport particles horizontally over large distances when the waves contain a trapped core (Pineda, 1999). Numerical simulation with the DJL suggests that the wave shown in Fig. 7 has the properties typically required for the presence of a trapped core. Finally, ISWs cause a Stokes drift, resulting in the unidirectional horizontal transport of dissolved substances and plankton and in a horizontal displacement of water constituents in the surface layer relative to those in deeper water layers. The effects caused by individual ISWs are amplified, since ISWs typically do not occur in isolation, but in wave trains. This is especially important in Lake Überlingen, where the number of ISWs in each wave train is particularly large.

\section{Conclusions}

The observations of this study support the conceptual picture of the propagation pattern and fate of ISWs at the basin scale in Upper Lake Constance summarized 
in Fig. 1c. The front of the ISW is depicted as a single line and the arrows indicate the direction of propagation (Fig. 1c). Since the basin-scale internal wave in Upper Lake Constance is a Kelvin wave, which propagates anti-clockwise around the lake, ISWs are generated at an internal front near the northern boundary of the main basin and the ISW front diminishes towards the centre of the main basin, where no ISWs were observed. From the main basin the ISW front propagates westwards towards Lake Überlingen. In the narrow sub-basin, Lake Überlingen, the basin-scale internal wave is not strongly affected by the Earth's rotation and therefore travels in the along-shore direction, with little variation in the amplitude of the wave front in the cross-shore direction. The ISW front is associated with the internal front of the basin-scale wave and also extends over the total width of Lake Überlingen. The ISWs propagate roughly parallel to the northern and southern boundaries, until they shoal upon the sloping topography of the western boundary. Many of the ISWs break at this terminal boundary in the cross-propagation direction. However, ISWs are also present at the reflected internal front of the basin-scale wave and propagate from the western end of Lake Überlingen eastwards. All along their path through the lake, the ISWs interact with the topography at their outer edges in the shallow waters of near-shore regions, probably resulting in localized wave breaking within the boundary region. Furthermore, a significant number of ISWs break far from the bottom boundary in the open water of Lake Überlingen (Preusse et al., 2012a). The breaking of ISWs in the open water is not a sporadic, isolated, local event, but extends over larger regions along the ISW front.

Acknowledgements The field experiments were supported by the technicians Joseph Halder, Beatrix Rosenberg and Alfred Sulger. The divers working with Martin Mörtl deployed the thermistors at the near shore moorings. We thank three reviewers for their comments and D.M. Livingstone for very detailed editorial suggestions. This work was financially supported by the University of Konstanz and the German Research Association (DFG, PE 701/4 1).

\section{References}

Aghsaee, P., L. Boegman \& K. G. Lamb, 2010. Breaking of shoaling internal solitary waves. Journal of Fluid Mechanics 659: 289417.
Alford, H. \& R. Pinkel, 2000. Observations of overturning in the thermocline: the context of ocean mixing. Journal of Physical Oceanography 30: 805832 .

Appt, J., J. Imberger \& H. Kobus, 2004. Basin scale motion in stratified upper Lake Constance. Limnology and Ocean ography 49: 919933.

Bäuerle, E., D. Ollinger \& J. Imberger, 1998. Some meteoro logical, hydrological, and hydrodynamical aspects of Upper Lake Constance. Archiv für Hydrobiologie Special Issues Advanced Limnology 53: 3183.

Boegman, L., \& G. N. Ivey, 2009. Flow separation and resus pension beneath shoaling nonlinear internal waves. Journal of Geophysical Research 144. doi:10.1029/2007JC004411.

Boegman, L., J. Imberger, G. N. Ivey \& J. P. Antenucci, 2003. High frequency internal waves in large stratified lakes. Limnology and Oceanography 48: 895919.

Boegman, L., G. N. Ivey \& J. Imberger, 2005. The degeneration of internal waves in lakes with sloping topography. Lim nology and Oceanography 50: 16201637.

Bourgault, D., M. D. Blokhina, R. Mirshak \& D. E. Kelley, 2007. Evolution of a shoaling internal solitary wavetrain. Geophysical Research Letters 34: L03601.

Bourgault, D., D. C. Janes \& P. S. Galbraith, 2011. Observations of a large amplitude internal wave train and its reflection off a steep slope. Journal of Physical Oceanography 41: 586600.

Chen, C. T. A. \& F. J. Millero, 1986. Precise thermodynamic properties for natural waters covering only the limnologi cal range. Limnology and Oceanography 31: 657662.

De La Fuente, A., K. Shimizu, Y. Nino \& J. Imberger, 2010. Nonlinear and weakly nonhydrostatic inviscid evolution of internal gravitational basin scale waves in a large, deep lake: Lake Constance. Journal of Geophysical Research Oceans 115: C12045.

Dorostkar, A. \& L. Boegman, 2013. Internal hydraulic jumps in a long narrow lake. Limnology and Oceanography. 58: 153172.

Filatov, N., A. Terzevik, R. Zdorovennov, V. Vlasenko, N. Stashchuk \& K. Hutter, 2012. Field studies of non linear internal waves in lakes on the Globe. In Hutter, K. (ed.), Nonlinear Internal Waves in Lakes. Advances in Geo physical and Environmental Mechanics and Mathematics. Springer, Berlin.

Hammack, J. L. \& H. Segur, 1974. Korteweg de Vries equation and water waves 2: comparison with experiments. Journal of Fluid Mechanics 65: 289314.

Helfrich, K. R. \& W. K. Melville, 2006. Long nonlinear internal waves. Annual Review of Fluid Mechanics 38: 395425.

Horn, D. A., J. Imberger \& G. N. Ivey, 2001. The degeneration of large scale interfacial gravity waves in lakes. Journal of Fluid Mechanics 434: 181207.

Huber, A. M. R., F. Peeters \& A. Lorke, 2011. Active and passive vertical motion of zooplankton in a lake. Limnol ogy and Oceanography 56: 695706.

Hutter, K., 2012. Nonlinear Internal Waves in Lakes. Advances in Geophysical and Environmental Mechanics and Math ematics. Springer, Berlin.

Hutter, K., G. Salvade, C. Spinedi, F. Zamboni \& E. Bäuerle, 1991. Large scale water movements in lakes. Aquatic Sciences 53: 100135.

Lamb, K. G., 2002. A numerical investigation of solitary internal waves with trapped cores formed via shoaling. Journal of Fluid Mechanics 451: 109144. 
Lamb, K. G. \& V. T. Nguyen, 2009. Calculating energy flux in internal solitary waves with an application to reflectance. Journal of Physical Oceanography 39: 559580

Lorke, A., 2007. Boundary mixing in the thermocline of a large lake. Journal of Geophysical Research 112: C09019.

Lorke, A., F. Peeters \& E. Bäuerle, 2006. High frequency internal waves in the littoral zone of a large lake. Lim nology and Oceanography 51: 19351939.

Macintyre, S., K. M. Flynn, R. Jellison \& J. R. Romero, 1999. Boundary mixing and nutrient fluxes in Mono Lake, Cali fornia. Limnology and Oceanography 4: 512529.

Michallet, H. \& G. N. Ivey, 1999. Experiments on mixing due to internal solitary waves breaking on uniform slopes. Journal of Geophysical Research Oceans 104: 1346713477.

Mortimer, C. H., 1974. Lake hydrodynamics. Mitteilungen Internationale Vereinigung für Theoretische und Ange wandte Limnologie 20: 129197.

Moum, J. N., D. M. Farmer, E. L. Shroyer, W. D. Smyth \& L. Armi, 2007. Dissipative losses in nonlinear internal waves propagating across the continental shelf. Journal of Phys ical Oceanography 37: 19891995.

Ostrovsky, L. A. \& Y. A. Stepanyants, 2005. Internal solitons in laboratory experiments: comparison with theoretical mod els. Chaos 15(3): 37111.

Ostrovsky, I., Y. Z. Yacobi, P. Walline \& I. Kalikhman, 1996. Seich induced mixing: its impact on lake productivity. Limnology and Oceanography 41: 323332.

Pineda, J., 1999. Circulation and larval distribution in internal tidal bore warm fronts. Limnology and Oceanography 44: 14001414.
Preusse, M., F. Peeters \& A. Lorke, 2010. Internal waves and the generation of turbulence in the thermocline of a large lake. Limnology and Oceanography 55: 23532365.

Preusse, M., H. Freistühler \& F. Peeters, 2012a. Seasonal vari ation of solitary wave properties in Lake Constance. Journal of Geophysical Research 117: C04026.

Preusse, M. M. Stastna, H. Freistühler \& F. Peeters, 2012b. Intrinsic breaking of internal solitary waves in a deep lake. PLOS ONE 7: e41674.

Stastna, M. \& K. G. Lamb, 2002. Large fully nonlinear internal solitary waves: the effect of background current. Physics of Fluids 14: 29872999.

Thorpe, S. A., 1977. Turbulence and mixing in a Scottish loch. Philosophical Transactions of the Royal Society London 286: 125181

Thorpe, S. A., I. Crofts \& A. Hall, 1972. The internal surge in Loch Ness. Nature 237: 9698.

Thorpe, S. A., J. M. Keen, R. Jiang \& U. Lemmin, 1996. High frequency internal waves in Lake Geneva. Philosophical Transactions of the Royal Society of London Series A Mathematical Physical and Engineering Sciences 354: 237257.

Vlasenko, V. \& K. Hutter, 2002a. Numerical experiments on the breaking of solitary internal waves over a slope shelf topog raphy. Journal of Physical Oceanography 32: 17791793.

Vlasenko, V. \& K. Hutter, 2002b. Transformation and disinte gration of strongly nonlinear internal waves by topography in stratified lakes. Annales Geophysicae 20: 20872103. 